\title{
XI. Memoir on the nature of fat substances
}

\section{Henry Braconnot}

To cite this article: Henry Braconnot $(1815) \mathrm{XI}$. Memoir on the nature of fat substances, Philosophical Magazine Series 1, 46:207, 29-41, DOI: 10.1080/14786441508638490

To link to this article: http://dx.doi.org/10.1080/14786441508638490

曲 Published online: 27 Jul 2009.

Submit your article to this journal $2 \pi$

III Article views: 3

Q View related articles $\asymp$ 
I do solemnly declare this to be the true method of curing Dutch herrings, as practised by me ard my men in curing the samples now exhibited by me.

\section{H. E. SIEvers.}

** On a minute examination of the samples of herrings produced to the committee, it appeared that those canght in the deep sea of the coast of Shetland were fatter and fuller of milts and roes than those caught on the coast of Yarmouth. Mr. Sievers stated, that herrings are generally known under three denominations, viz. the St. Michael's herring, the Highland herring, and the long shotten herring. That the deep sea fishing is carried on in sloops, each carrying ten or twelve hands, that they go to Shetland to clear out according to act of parliament about 16 th June, and have then to return to commence the fishery at Buchaness off Peterhead on the 24th of June; that by being thus at present obliged to go first to Sheerness to clear out, they suffer great disadvanges by delays from wind and weather, in a voyage of 300 miles before they can commence the fishery at Buchaness; and that the Dutch have an advantage from not being oblixed to go to Shetland; that the herrings caught in the reep sea of Buchaness are large, fat, and fullbellied; they are also richer in flavour, and more esteemed for home consumption and the continent, bat do not keep so well as the lanker herrings caught near Yarmouth, which last are better calculated for the West Indin markets; that the Yarnouth fishery is curried on in September and October, as the herriugs come down the German ocean.

XI. Memoir on the Nalure of fat Substances. By HENRY Braconnot, Professor of Natural History, and Director of the Garden of Plants at Nanci*.

H at being formed of one substance, having the same essential properties, and differing only by its firmer or weaker consistence: hence the various denominations of suet, Jard, fat, marrow, \&ce. admicted by the ancients. This consistence of fat varies in fact in a manner truly remarkable: thus it is hard in the ruminating quadrupeds, softer in man than in the animals which tive upon vegetables only, almost liquid in the amphibions mammiferz, the cetacei, as well as in all the carnivorous animals, whether birds, reptiles, fishes, or insects. Not only does the consistence of the fat vary in the various kinds of animals, but also accorri-

* Annales de Chimic, tome xciii. p. 225 . 
ing to the regions which they occupy, and according to the age. sex, and physical constitution of the individual. It is very hard in the neighbourhood of the kidneys, softer in the epiploon, the mesentery, the intestines, and around other moveable viscera: it is almost liquid when it coats the orbitary cavities. Certain accidental dispositions also produce remarkable changes in the consistence of the fat, as is observed in the steatoma, the old hernix of the epiploon, and in certain sebaceous tumours, which are sometimes as hard as a calculus.

On reflecting on this infinite variation in the consistence of fat, and seeing besides that suet and oil secm in be the two extremes of this consistence, it appeared to me that with these two bodies mixed in various proportions, nature might produce that diversity of fat bodies which we observe in organized beings. Deeply penetrated with this idea, which appeared specious at least, I endeavoured to find among the chemienl reagents some substances capable of separating the suet and the oil which 1 supposed to exist in all the fats, but I found none which could effect my purpose; when at last a very simple method presenter itself to my mind, and fully confirmed my conjecture. It is founded on the physical property peculiar to oil, of being taken up greedily by gray paper, which is not tonched by suet or tallow, in its state of purity. It was by applying this process to the analysis of fatty substances that I succeeded in discovering the two substances which compose them, and in determining their respective proportions in the following substances.

\section{Melted Buller.}

This article was forcibly compressed for several days at the temperature of zero, between several folds of coarse gray paper, taking care to renew it until it was no longer stained: when again pressed as at first, at a temperature of $15^{\circ}$ Reaumur, a white brittle matter was obtained, at least as compact as the butter of cocoa or the hardest suet, of a very decided smell and taste of suet. Suspecting that it might still retain some traces of oleaginous matter, it was melted, and I mixed with it a small quantity of volatile oil of turpentine: the matter, when hardened and pressed to absolute dryness in blotting-paper, presented a substance which was kept in fusion during some time: when hardened, it was dry, broke with lustre, and melted at the same degree of heat as beef suet, a temperature which $I$ found to be $46^{\circ}$ of Reaumur, while we find that mutton suet requires a temperature of $49^{\circ}$. The suet of cow butter is, in fact, similar to that which exists in the various parts of the body of this animal : a result which might lead to some phyciological conse"luences. In mier 1 , obtain the cil of butter, I moistened with 
warm water the gray paper, in which the butter had been conpressed; then I made a ball or knot of it, which was submitted to the action of the press, and there revulted an oil perfectly fluid. We may also obtain a part of the oil of butter by pouring it into a vessel fumished at its lower part with an aperture which is to be nncorked when the butter freezes: after som** time, and at a noderate temperature, a considerable quantity of the oil flows ont, which may be advantageously used in the preparation of certain dishes. The oil of butter obtained at a low temperature is a liquid of a yellow colour, like most of the fixed vegetable oils, of a smell and a taste peculiar to the butter. I had tried, but without success, to take off from this on its colouring matter, by treating it with ether. The sulphuric acid when properly employed seems to destroy this yellow colour, for the oil becomes colourless, particularly after having been treated with a little argil.

One hundred parts of melted butter of a good quality made during summer, yielded as a product at the tenperature of zero:

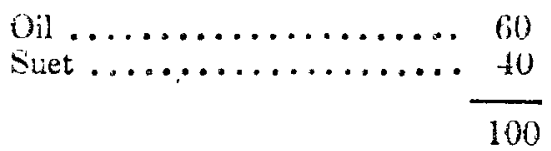

But these proportions are liable to variation, according to the phraical cosstitution of the cow, the nature of her food, and the place where she is domiciled. Thus the butter shich is brought to us from the Vosges mountains is of a fine yellow colour; it is much more oily and more esteened than that which is procurcd in plain or low countries, which last is paler, firmer, and contains more suet. This last substance is still more abundant if the cows have been fed upon dry forage; when they furnish it hard, compact butter, of a dull white and of an inferior guality. One hundred parts of this winter butter from the Vosges yelder a) the tamperature of zero,

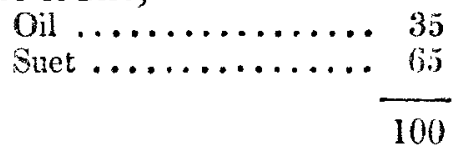

We see by these respective quantities the enormous dificicuce between summer and winter butter : but if the proportion of sust and oil varies in the same animal, according to different circumstarces, a fortiori, ought it to vary in the different kinds of animals which yielded it. To judge from its consistence, the buiter of cows and goats ought to contain a much greater quantit: of suet than that of sheep, asses, and mars. "I"vit of wum:

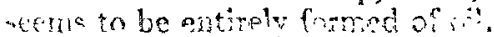




\section{Of the Fat of Pork, or Lard.}

Like melted butter and the other fats, that of pork has been hitherto regarded as a homogeneous body. M. Vogel consisering it as such, submitted it to a series of experiments in a memoir particularly directed to the examination of this substance*. Recent hogs-lard, well purified, was long pressed in gray paper, as we have directed in the case of butter, and a suet was obtained of the consistence of soft wax; as this suet seemed to me still to retain some oil, it was purified by melting it in oil of turpentine, and by submitting the mixture when cold to new compressions in gray paper, there remained a sebaceous matter, which was held in fusion some time to extract the small quantity of oil of turpentine which it might contain. This absolute suet at the ordinary temperature of the atmosphere is dry, brittle, and inodorous, like the other suets in their state of purity ; but it differs from them in being almost transparent or semi-diaphanous like certain calcedonies; it is softened or reduced by the fingers with great difficulty, although more easily than beef suet, and has not such a greasy appearance, but it is soft and soapy to the touch like whale fat, like which it leaves a brilliant lustre when it is rubbed on bodies: in these respects it resembles spermaceti : it has, however, but a grainy crystallization, not decided; and it is less soluble in boiling alcohol, although the latter takes up enough to make the liquid turbid on cooling, and there are separated flakes of greasy matter on the addition of nitre.

The suet of pork requires for its fusion a temperature a little higher than that which is necessary for melting whale fat.

The same suet, like all those obtained from the different fatty substances, undergoes under the action of the acids and alkalis a very remarkable alteration, in so much as it is converted into t:wo substances which did not exist before ; namely, adjpocire and oil, both extremely soluble in warm alcohol. This transformation is entirely and immediately affected by pouring into one part of pork suet melted, half a part of sulphuric acid, and by immediately diluting the mixture with a quantity of boiling water in order to take up the acid and to separate the two fat ratters newly formed, which we shall presently make known. I shall content myself with observing at present, that the suet of pork on being converted into adipocire and oil is susceptible of forming with the sulphuric acid a soapy combination sufficiently intimate, and even soluble in water like soap, which does not precisely happen on treating beef or mutton suet in the same way, although all the fat substances, in changing their nature,

* Annales de Chimie, tome lviii. p. 154.

also 
also saturate one part of the properties of the sul, huric acid, as they saturate that of the allalies. Potash in saponifying pork suet transforms it aloo into atlpocire and oil *. The gray paper in which the lard had been compressed was strongly penetrated with oil; it was mointeired with hot water and subjected to the action of the press, after having been inclosed in a strong cloth, and we obtainced an oil which was easily separated from the water. The oil of lard is a colourless fluid like water, of a peculitir tate. When exposed to a greater degree of cold it tioes not freeze, if it has been obtained at a low temperature. One hundred parts of hogs-lard at zero of the thermonieter furnished me as constituent principles:

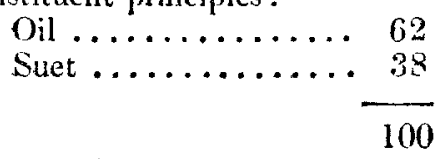

If the compression of the lard has been effected at a middling temperature, we obtain a greater quantity of oil ; but in this case the latter retains some suet, and is hardened into a gelatinous consistence when exposed to the cold.

\section{Beef Marrout.}

When slightly pressed between the fingers, this substance, taken from the interior of the thigh-bone, seemed entirely formed of an innumerable multitude of very distinct transparent bags containing the marrow. We shall see presently that this stmeture is not peculiai to the marrow, but that it is common to all fat substances in the animal kingdom. When well washed and freed from its rascular envelopes by fusion, beef marrow had a firm consistence at the temperature of $-\cdot 2^{\circ} \mathrm{R}$.; in this state it was pressed in gray paper until it ceased to stain it, and I obtained

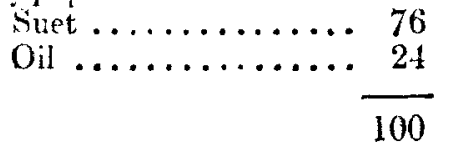

* I had dissolred in a grcat quantity of water, soap procured from hogslatd and potash, with a view to examine the substance described by MI. Cheveul under the name of Margarine; but ustead of obtaining a pearly substance in bilitiats scals, nothmg was forncd after some days but a very trithing preciuitate, which whon collected on the filter had the appearance of gelatimous alhumen newly precipitated; when dned, it was at a dull white, which became shining when rubbed, and was reduced between the fingers to an impalpable powder, soft and soapy to the touch. This matter, insoloble in wate:, was composed of an adipocirous substance, potash, and a small quantity of lime. Probably it is not this substance which $M$. Chevreul has described as margarine: I contess candidly that I am ignorant of the circumstances which may have concurred in the formation of this last substance.

Vol, 46. No. 207. July 1815. 
But the suet thus obtained was soft, and consequently still retained a little oil : in order to purify it completely, it was melted, and I added to it an equal quantity of volatile oil of turpentine.-The mixture when cooled and pressed as before, fur nished a suet which did not differ much from beef suet: it seemed, however, to be a little imore fusible. The oil of beef marrow is an almost colourless liquid, and has a disagreeable taste.

\section{Mutton Marow.}

It is nearly of the same structure as that of beef; but it contains a much more considerable quantity of oil. Thus 100 parts of mutton marrow washed and melted gave me at the temperature of $-2^{\circ}$ Reaumur: Suet 26 ; oil 74 .

The suet of mutton marrow, purified as above, has the same appearance with common mutton suet; like which it is of a dry and brittle consistence, which admits of its being reduced to powder ; but it is more fusible, for it melts at $41^{\circ}$ of Reaumur, wheress common mutton suet from the kidneys fuses only at the tempcrature of $49^{\prime}$, which seems to establish a difference between those two substances; which have besides the property of waxing substances, like bees-wax.

\section{Goose Grease.}

One hundred parts of this grease well washed, after being ob. tained from a roasted goose, yielded as results, at the temperature of -2 R: Oil 68 ; suet 32 .

Goose grease purified with ence of turpentine has the whiteness, hardness, dryness, and fracture of common beef suet; but it is nuch more fusible, for it begins to melt at $35^{\circ} \mathrm{R}$. The cill of goose is a liquid slightly coloured, and has the taste and smell peculiar to the goose.

\section{Grease of Ducrss.}

This grease at the temperature of $10^{\circ}+0 \mathrm{R}$. has the consis:crice of half-frozen olive oil ; and at $20^{\circ}$ of the same thermometer it is perfectly fluid. One hundred parts of this grease at $-2^{\circ} \mathrm{R}$. produced : Oil 72 ; suet 28 .

The oil of ducks possesses the taste, smell, and yellowish colour which is visible in the fat of the animals. The suet when very pure is white, not very sapid, inodorous, dry, and breaks like wax. It differs from goose suet in so far as it affects a decisive crystalline form: besides, it requires $42^{\circ} R$. to melt it. It is dissolved in boiling alcohol, but in a small quantity.

Grease of Turkeys.

One hundred parts yielded at the temperature of zero: Oil 74 ; suct 26 . The oil is of a yellowish colour, and has the 
taste and smell peculiar to the animal. The suet when purified by oil of turpentine, is not so dry and fragile as that of duchs: it melts at $36: R$.

\section{Olive Oil.}

The oil extracted from olives is no longer, as has been supposed, an immediate simple principle : it is composed, like all the fat bodies, of two distinct substances. Olive oil of good quality was exposed for two days to the itrinperature of $-5^{\circ} \mathrm{R}$.: it forued into a mass of the consistence of honey : when pressed at the same degree of cold in gray paper, a suet was obsained of a brilliant white, inodorous, not very sapid, and as firm as beef suet, but of far greater fusibility, for it melted at $16^{\circ} R$. The alkalies by acting on this snet metamorphose it into oil soluble in alcohol and iuto an adipocire which melts at $50^{\circ} \mathrm{R}$. only. The oil of olives thus isolated from its suet, and penetrating the paper in which it had been pressed, was separated from the paper by humecting it with warm water, and pressing it again. This oil has the smell and taste of olive oil ; but when exposed to a temperature of $10^{3} R$. it does not freeze; although exposed to a more considerable cold, a small quantity of suet still leaves it. The property which this oil has of not freezing and not becoming rancid, renders it valuinible in the arts, and particularly to watch-makers; but it has nevertheless a great inconvenience when employed in its common state; namely, as it freezes at a middling degree of cold, there must be a consequent irregularity in the movements of the delicate machinery to which it is applied. The oil of olives, however, when deprived of its suet is absolutely free from this complaint, and has all the qualities which we can wish. 100 parts of olive oil at the temperathre of $-\tilde{5}^{2} \mathrm{R}$., produced:

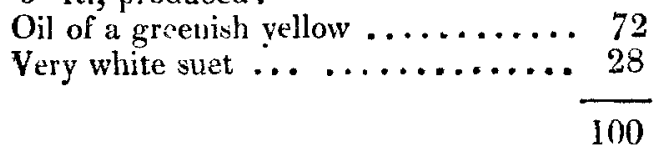

Without reckoning the frequent falsifications to which olive oil is subject in its purest state, it is not always identical in the proportion of its principles: thus the virgin oil, or that which is obtained by a slight pressure of the olives, contains much less suet than that which comes afterwards: it is therefore improper for the manufacture of soap, and we shall presently see that the snet or adipocire is indispensable in the manufacture of soap of good quality.

\section{Oil of sweet Almonds.}

One hundred parts of oil of sweet almonds, frozen at $\xi^{\circ}$ or $9^{\circ}$ C 2 
below zero, were treated as above; and yielded : yellow oil 76 ; very white suet 24 .

The above suct rescmbles the rest in its colour and consintence; but it is distinguished from them by its extreme fusibility; for it molts at $5^{5}$ of Reaumur, and freezes again on the temperature being lowered. This suet, which is so fusible, is transformed by the action of potash into oil, and into an adipocire which melts at 4 ; only; which is very remarkable. The vil of sweet almonis deprived of its suet resists the greatest cold without losing its fluidity.

\section{Oil of Colsa.}

By cxposing this oil to the freezing temperature, and even ahove it, a part of its solich matter is sejarated from it in the form of round globules; it is a mistake in Fourcroy to allege that it is less capable of freeing that oil of sweet almonds, since the latter requires at least $7^{\circ}$ or $S^{\prime}$ below zero. At $-3^{\circ} \mathrm{R}$. the oil of colsa goes into a mass much firmer than nelted butter, and of the yellow coiour of wax. 100 parts of this substance, pressed at the same temperature in griy paper, yielded:

$$
\begin{aligned}
& \text { Oil of a tine yellow ............ } 54 \\
& \text { Suet, very white } \ldots \ldots \ldots \ldots \ldots \ldots, 46 \\
& 100
\end{aligned}
$$

This suet olitained after the first pressure had still a slight vellowish tinge; but when pressed a second time, after having been melted, and then frozen at the temperature of $2^{\circ} \mathrm{R}$. a brilliant white was obtained : it is inodoronc, not very sapid, and affeets a spherical crystallization; it is a little less fusible than the suet of oil of sweet alnonds, and melts at $6^{\circ} \mathrm{R}$. Its chemical characters seem to distinguish it from the other suets; for, instead of being converted into adipocire and oil by the action of the acids, it only yields a thick and thready mass like turpentine: time produces nearly the same effects as the acids on these oils. The oil of colsa, deprived of its solid matter, is no longer susceptible of freezing: it merely possesses the colour, smell, and taste, which we recongise in the oil of colsa of commerce.

The experiments just detailed on the fat principles, authorize $u$ : to think that all the rest are similarly composed of fluid oil and a solid substance which we find even in the oils which have the least disposition to freeze, as recent linseed oil, which deposits during a cold night very regular conical crystals, as observed by Professor Goettling. Most of the volatile oils also contain concrete crystallizable substances, sometimes analogous to camphor: hence it would seem that camphor is to the volatile oils what suet is to fat. Certain volatile oils, however, seem to con- 
tain concrete substances very different from true camphor, like those which probably exist in the volatile oil of roses and in that of the elder-tree which have the consistence of butter. We may say the same of the volatile oils furnished by the umbelliferous plants; such as the parsley, fennel, dill, cumin, and aniseed*, all of which have the property of freezing in a very slight degree of cold.

\section{Experiments upon Suct.}

Physiologists are of opinion generally, that the fit has its seat in the cellular texture. Ou examining with the naked eye suet as we meet with it in animals, i. e. that which enrelops the kidnevs in the ruminating quadrupeds, we find it ar ranged in conchoid, square, or orbicular masses, separated from eacli other by membranous laminx. If we examine each of these naxes attentively, we see them entirely formed of an iunumerable mu!titude of oblong globules, transparent and brilliant like a crytallized salt, and which seem tied to each other by a very loose membranous texture, like the grains of starch in a boiled potatoe. We may separate these globules from each other by slightly macerating the suet in cold water, and shaking the whole over a hair sieve. We then obtain a powder which resembles starch when it has been dried on gray paper. These membranous vesicles containing the suet, did not appear to me to have the same structure as the cellulis texture, which is formed, as we know, by the junction and mutual adherence of the collules which communicate with each other.

In order to ascertain if those membranous cysts serving as a reservoir to the fat had any onifices to allow it to escape, they were exposed to different degrees of heat with water; but it was only at a heat of $65^{\circ}$ of Rinmur that some bublites of greasy matter melted, began to aypear on the surface of the liquor, and even at the bonliag point. a great nunber of those isolited vesicles still existed without having given out any grease: hence it follows that every globuls of sict is contained exactly in a membranous vesicular envelope, which hinders it from separating, even at a heat much greater than that which is necessery for melting it. The adipose glands of Malpighi, which no :uthor since his day has discovered, are they the same organs with those vesicles filled with snet? I um not inclined to think so, since we observe the latter very distinctly withont the assist-

* On cxamining sone casks which har contained amserd oil, I found the whole inside fringed with a brllian dry crystallzed cuatter, which it was easy to collect, even in a considerable quantrty; and I theught of examining these crystals more muntely: bat huvog left them duing a whole summer exposed to the solar light, $I$ found then resuived into a tilick liquid which lost the faculty of crystalliz'ng. 
ance of the microscope, in the fats which are not too soft. However this may be, the fatty substance, liquid or solid, fixed or volatile, and wherever we meet with it in organized beings, presents nearly tive same structure in the reservoir where nature has placed it.-To give some examples of this taken frum! the vegetable kingdom, I shall cite among the plants which vecrete the sebaceo-cirous matter, the corpuseles which constitute the dust of the lcaves and fruits which Proust has found analogous to wax. On examining this dust with the microscope, we see it formed of transparent grains, the form of which varies with the species: an analogous configuration may be remarked in the waxy substance which coats the surface of myrtle-beries. It is sufficient to press strongly the latter, in order to free them of the wax, which has a grainy and amylaceous appearance. The volatile oils are also contained in small membranous bladders, as is proved by the epithets of vesicular, miliary, globulous glands, which botanists have given to these small reservoirs filled with volatile oil. I shall not inquire, with physiologints, if the secretion of the suet or of the fat operates, as they pretend, by the extremitics of the arteries, or by oozing through their tunics: one thing is certain, that this secretion takes piace under certain circumstances with incredible celerity.

Suet does not exist in a state of absolute purity in animals, and hitherto it has been unknown any where in that state: the firmest which can be procured still contains a certain quantity of oil; that which incloses the kidneys in sheep contains more than that of bullocks: the tallow used for candles also furnishes a great quantity; for 100 parts at the temperature of 5 " R. yielded 30 parts of oil. We succed in depriving these fatty substances of their oil by melting them and adding spirit of turpentine newly distilled; the mixture, frozen and pressed in a cloth, or what is still better in gray paper, leaves the suet in a state of purity: it is culy necessary to keep it in fusion for some time, and allow it to cool. Pure mutton suet thus obtained is a substance very analogous to wax, and seems even to be more compact, drier, and more brittle; but it has not the same ductility, for it is easily reduced to powder; it likewise waxes bodies, giving them a glossy appearance like bees-wax, and emitting the same noise on being rubbed $\%$. Pure mutton suet melts at the temperature of $49^{\circ} \mathrm{R}$ : yellow wax meits precisely at the same de-

* Fatty substances as well as certain families of urganacd beings secm to contan a great quantity of species which pass to each other by shades so slight that it is diticult to group them nell: thus we are froquently cobarrassed, when it is wanted to ratuge this or that fatty substance, whether to do so among the waxes, the suets, or the adipocires, and it must ce wimitied that the last three genera are purely artifiejal. 
rree of heat, according to Bostock; but this suet is less soluble than wax, and than the white fat of whales in boiling alcohol. The latter may, however, dissolve to make the liquor turbid on cooling. Boiling ether dissolves it better, and upon cooling a precipitate is formed in large gelatinous flakes.

Pure beef suet is white, although having naturally a yeliow colour when it is not purified, which makes it be supposed that this colour is owing to oil: it has a greasier aspect than mutton suet; it is besides more fusible, since it is liquefied at $46^{\circ} \mathrm{P}$. Thus it is less adapted for candles than pure mutton suet, which when obtained by some easy process will afford the means of supplying the place of wax in some circumstances.

In order to complete what I have said as to suet, I shall enter upon some details respecting its singular metamorphosis into several fat substances by the action of the acids and alkalies, which will lead me to examine the results of saponification and rancidity.

\section{Aciion of the Sulphuric Acid upon Suet.}

Chemists have contented themselves with saying, that the sulphuric acid decomposes and carbonizes fat, particularly with the aid of heat; but it does not apjear that they have examined with care the results of this action. If we pour concentrated sulphuric acid into melted suet, there is immediately formed by agitation a true combination, in which the acidity has in a grea: measure disappeared. T'o one part of melted mutton suet was added half a pint of sulphtire acid, and the combination, which was of a reddish colour, was diluted in a great quantity of boiling water, which seized the sulphuric acid and abandoned the greasy matter. 'The latter, after having been washed several times, had nut perfectly lost it, reight, lut it had acquired a less firm consistence than the suet empioced: the latter was in fact transformed into a small quantity of oil, and into a substance very analogous to wax. In order to isolate these two sulstances from each other, the oleo-cirous mass, when well cleansed from sulphuric acid, was melied, and the half of its weight of alcohol was added to it; the uision took place immediately with a promptitude truly extraordinary: upon cooling there resulted a harl mass, which was folded in new linen; by gradual pressure the alcohol was expelled charged with oily matter, and the compression was finished in gray paper. The solid matter thus obtained was not yet perfectly white, although treated severai times with alcohol; but by means of warm ether, which also dissolves it with extreme facility, we succeed much better in obtaining it of a perfect whitenes. This substance is dry, sonorous like C. 4 
hard bodies, susceptible of being reduced into powder, breaking with more lustre than white wax, and having the same taste, smell, and properties of waxing bodies, but it has not the same tenacity; and instead of receiving the various impressions which the fingers give it, when it is slightly softened, it is reduced into a lamellous powder: in this respect it resembles the Louisiana wax; but the latter melts at the temperature of $34^{\circ} \mathrm{R}$. according to Bostock, whereas the matter in question does not enter into fusion sooner than $53^{\circ}$, and on cooling it does not crystallize better than common wax: it is also infinitely less fusible than the adipocire of dead bodies, although it secus in other respects to resemble it much in its chemical propertics, and particularly in the faculty which it shares with the latter, of being combined immediately with the alkalies to form suap; whereas the other fatty substances do not become susceptible of uniting completely with it until after a long ebullition, and after undergoing an alteration which makes them closely resemble the waxy substance the properties of which we are enileavouring to asecrtain. The latter has such an aptitude to combine with the alkalies, that it disengages the carbonic acid from the alkaline carbonates to form soap: this property is common to certain fat bodies only easily soluble in alcohol, like adipocire and the oil of sonps; that of churchyards, and perhaps also that of nushrooms, as well as their oil.

The same substance contracts with ammonia a combination soluble in water, but the soapy liquor deposits a pant of this combination.

When this fat substance is melted, it unites with and is dissolved in alcohol in every proportion and with astonishing facility. If the liquid contains but a small quantity of aleohol, it goes into a mass more er less solid upon cooling; but when the liquor is diluted with a greater quantity of alcohol, $n$ white faky and abundant precipitate is formed. In the cold, alcohol dissolves but a very small quantity, beeause it has to overcome the force of cohesion which this substance opposes to it: thus 100 parts of alcohol at the temperature of $10^{\circ} \mathrm{R}$. only dissolved $21 \cdot 2$. Warm ether dissolves it at least as rapidly as warm alcohol, i. $e$. in every proportion: when reduced to powder and put aside to digest with 100 parts of ether, the latter dissolved 12 parts of cirous nuatter at $10^{\circ} \mathrm{R}$. The volatile oil of turpentine at the same temperature, only takes the twentieth part of its weight.

If we compare the totality of the physical and chemical properties of this substance with that of the other fat bodics, we shall find that among the latter the adipocire of the churchyards 


\section{Process for curing Herrings, Pilchards, Mackercl, हfe. 41}

seems to be that which resembles it the most : consequently, and without hesitation, I regard it as a particular species in the genus adipocire, alrealy very numerous in species and varieties.

[To be continued.]

XII. Process for curing Herrings, Palchards, Mackerel, Sprats, sc. by Immersion in Brine of British "solid Salt." By Mr. Phillips London, of Cannon Strett.*

SIR, - I BEG of you to present my respectful compliments to the gentlemen of the Conmittee, and also to the Society, for their vote of thanks conveyed to me in your letters of 9 th March and 21 st of April last, expressing also their hopes that I would persevere in preserving mackerel upon the principle which I had the honour to communicate to them in May 1813, and which, they were plensed to sny, they regard as an object of much national consequence.

I have not, sir, been inattentive to the object; on the contrary, I have caused to be cured this last season at Ramsgate, upwards of twenty-five thousand mackerel.

'There were cured at the sane place this autumn, and sent to the West Indies, upwards of three hundred barrels of herrings, and in the last spring, about tilty barrels of sprats, all preserved upon the principles which the society did me the honour so highly to approve, and which, I am fully persuaded, is the most effectual, ceconomical and expeditious method of curing fish ever practised; and I an strengthened in this hope by observing in the fishing regulating bill, now depending, that encouragement is held out by a new clanse introduced expressly for the purpose.

In expectation that the mole of curing fich by immersion in fully saturated brine of solid salt may bectuse very general, particularly for herrings, I am induced to inclose to the Society the process more fully explained than it is in their volume for 1813 , ind calculated for curing tish on shore, and in any situation howcrer exposed, even witiout any covering, as you will rearily conteive that a surplns of salt on the surface of the brine will always meet and quickly saturate any rain whatever that may fall into the reservoirs.

I am, with respect and esteem, sir, Your obedient servant,

37, Cannm Strcet, Dcc. 6, 1014.

Phillips LoNdon.

To C. Taylor, M.D. Sec.

* Irom Transuctions of the Suciety for the Encourugenent of Arts, Mamtu fucturs and Commere, vol. xxais. for 1814.-The thank of the Society were roted to Ar. Loudon for this communication. 